\title{
Using Telemedicine to Assess and Manage Psychosis Among Outpatients with Neurodegenerative
} Disease

\author{
Craig Chepke (1D ${ }^{1-3}$ \\ Lynn W Shaughnessy ${ }^{4}$ \\ Stephen Brunton ${ }^{5,6}$ \\ Jill G Farmer ${ }^{7,8}$ \\ Andrew S Rosenzweig' \\ George T Grossberg ${ }^{10}$ \\ Wendy L Wright"
}

'Excel Psychiatric Associates, Huntersville, NC, USA; ${ }^{2}$ Atrium Health, Charlotte, NC, USA; ${ }^{3}$ University of North Carolina School of Medicine, Chapel Hill, NC, USA; ${ }^{4}$ Department of Neurology, Beth Israel Deaconess Medical Center, Harvard Medical School, Boston, MA, USA; ${ }^{5}$ Primary Care Education Consortium, Winnsboro, SC, USA; ${ }^{6}$ Department of Family Medicine, Touro University, Vallejo, CA, USA;

7Parkinson's Disease and Movement Disorder Program, Center for Neurosciences, Robert Wood Johnson University Hospital Hamilton,

Lawrenceville, NJ, USA; ${ }^{8}$ Department of Emergency Medicine, Drexel College of Medicine, Philadelphia, PA, USA;

${ }^{9}$ Forefront TeleCare, Providence, RI, USA; ${ }^{10}$ Department of Psychiatry, St. Louis University School of Medicine, St. Louis, MO, USA; "Wright \& Associates Family Health Care, Concord and Amherst, $\mathrm{NH}$, USA
Correspondence: Craig Chepke

Email cchepke@excelpsychiatric.com

\begin{abstract}
The presence of hallucinations and delusions in patients with neurodegenerative disease correlates negatively with function, cognition, quality of life, and survival. When these patients still have insight, the treatment of mild hallucinations may reduce the risk of progression to more severe symptoms, specifically hallucinations without insight or delusions. On October 22, 2020, a multidisciplinary consensus panel comprising United States-based experts in geriatric psychiatry, geriatric medicine, family medicine, movement disorders, and neuropsychology was convened remotely to discuss best practices for using telemedicine to evaluate, diagnose, and treat psychosis in patients with neurodegenerative diseases. This review reflects the opinions and recommendations discussed at this meeting. Despite drawbacks, telemedicine can offer several advantages over in-person care, particularly for older adults, and may be a unique opportunity for care of patients with neuropsychiatric symptoms. While telemedicine may not be suitable for all patients, it allows the involvement of specialists from multiple geographic locations and the extension of care to homebound individuals. Patients with neurodegenerative diseases who are likely to become homebound as the disease advances may benefit greatly from telemedicine as a standard of care. Healthcare provided via telemedicine should be nothing less than what would be offered to the patient in person. Telemedicine may present some difficulties, including technological issues and inherent constraints of remote care, but with proper planning many problems could be diminished. Technical issues associated with telemedicine are inevitable but may be partially offset by providing clear directions ahead of any televisit to ensure connectivity and access to the videoconferencing platform. Alternative procedures to communicate should be established in the eventuality of technological issues. Using these strategies, telemedicine can serve as a valuable complement to traditional in-person practices for the diagnosis and management of hallucinations and delusions associated with Parkinson's disease psychosis or dementia-related psychosis.
\end{abstract}

Keywords: telemedicine, Parkinson's disease, psychosis, primary care, hallucinations, delusions

\section{Introduction}

In the United States (US), the prevalence of neurodegenerative disease continues to rise with 8 million estimated to have dementia and 1 million to have Parkinson's disease. $^{1-4}$ Although these diseases are often identified on the basis of their characteristic symptoms involving motor dysfunction and/or cognitive decline, neuropsychiatric symptoms such as hallucinations and delusions also frequently occur. Depending on etiology, $40-60 \%$ of these patients experience hallucinations and/or delusions (ie, psychosis) at some point during their illness. ${ }^{5,6}$ The presence 
of hallucinations and delusions correlates negatively with function, cognition, quality of life, and survival in patients with neurodegenerative diseases. ${ }^{7-10}$ However, some studies have shown that treating mild hallucinations, occurring when patients have insight, reduced the risk of progression to more severe symptoms, specifically hallucinations without insight or delusions, ${ }^{11}$ underscoring the need for early identification and management of psychosis in patients with hallucinations or delusions related to neurodegenerative disease.

When the coronavirus disease 2019 (COVID-19) pandemic was declared a national emergency on March 13, 2020 , it triggered a decline in routine care, owing to a variety of factors, including patient self-isolation measures, reassignment of medical staff to pandemic efforts, and facility closures. ${ }^{12-14}$ For example, in the US, $41 \%$ of adults reported avoiding medical care because of concerns over COVID-19, ${ }^{12}$ and according to a survey undertaken by the World Health Organization, 59\% of member countries reported government-imposed restrictions on outpatient care for noncommunicable diseases. ${ }^{13}$

To mitigate the disruptions to in-person access to medical professionals, maintain patient care, and reduce infection risk, the use of telemedicine-the practice of exchanging medical information between different locations via electronic means (eg, videoconference, telephone, email) to support patient health-has increased during the pandemic. ${ }^{13,15-18}$ On the basis of an analysis of electronic intake data performed in the US, the field of neurology saw a 19\% decrease in the number of overall medical visits from the week before the pandemic was declared (March 1-7, 2020) to December 31, 2020, but a $17 \%$ increase in the number of telemedicine visits. ${ }^{14}$ Despite the substantial drawbacks of conducting medical care with video (eg, technology restraints, patients with hearing/visual impairment), telemedicine can still offer several advantages over in-person care, particularly for elderly patients, and is now considered a unique opportunity for care of patients with neuropsychiatric symptoms that could extend well after the global COVID-19 pandemic subsides. $^{19,20}$

There is evidence that use of telemedicine to manage patients with neurodegenerative diseases is feasible. ${ }^{21,22}$ The concordance between in-person-based and telemedicinebased diagnosis of dementia is high, ${ }^{23-26}$ and no statistically significant differences in clinical outcomes or quality of life were found in patients with Parkinson's disease randomized to receive in-person versus telemedicine visits following an initial in-person visit. ${ }^{27} \mathrm{~A}$ recent systematic review analyzed 17 studies of the efficacy of telemedicine for dementia care and reported that while 5 studies excluded patients with visual or hearing disability, all 17 studies found that both patients and care partners were satisfied with the telecare received. ${ }^{28}$ Data also suggest that patients with hallucinations and delusions can be reliably assessed via videoconferencing, without a worsening in symptoms. ${ }^{29}$ Additionally, remote assessments have been used in the clinical trial setting to evaluate the efficacy of antipsychotics in patients with schizophrenia. ${ }^{30,31}$

Diagnosis and management of patients with hallucinations and delusions related to neurodegenerative disease requires simultaneous consideration of characteristics of the disease, aging, and psychosis. Although numerous professional medical organizations have released guidance documents relating to the integration of telemedicine into daily clinical practice, ${ }^{32-35}$ none of the documents are specific to the management of hallucinations and delusions in patients with neurodegenerative diseases. To address this need for guidance, on October 22, 2020, a multidisciplinary consensus panel comprising US-based experts in geriatric psychiatry, movement disorders, and neuropsychology was convened remotely to discuss best practices for using telemedicine to diagnose and treat psychosis in patients with neurodegenerative diseases. This report summarizes the panel's recommendations on the outpatient management of patients with hallucinations, delusions, or both associated with Parkinson's disease psychosis (PDP) or dementiarelated psychosis (DRP). Additionally, a literature search for PubMed articles using the following keywords with different combinations - telemedicine, telehealth, psychosis, hallucinations, delusions, geriatric population, geriatric psychiatry, neurodegenerative disease, dementia-related psychosis, Parkinson's disease, primary care, outpatient management - was conducted to describe the current evidence for use of telemedicine in patients with hallucinations and delusions and neurodegenerative diseases.

\section{Advantages of Using Telemedicine Among Outpatients with PDP or DRP}

Telemedicine offers several advantages over in-person healthcare visits, many of which are particularly relevant to older patients. Furthermore, telemedicine has been demonstrated to be feasible and acceptable in geriatric patients and can improve health outcomes. ${ }^{36}$ The 
COVID-19 pandemic necessitated avoiding public places, but exposure to other common infectious diseases is a continuing concern for older patients with health issues. In addition to minimizing infection risk, telemedicine eliminates travel requirements. ${ }^{37,38}$ This is particularly important because the ability of individuals with neurodegenerative diseases to safely operate a motor vehicle declines over time, ${ }^{39}$ possibly culminating in the need to cease driving altogether. Spouses or partners who might be the primary or sole care partner and of similar age as the patient may also have minimal ability to transport the patient. To compensate for the loss of independence, patients and care partners may have to rely on public transportation or livery services (eg, taxis, rideshares), but these types of services are scarce or unavailable in some regions, and where they are available, it may be difficult for individuals with DRP or PDP to coordinate or access these services because of cognitive impairment and/or physical disability. As a consequence, family members may be faced with the additional responsibility of chauffeuring patients or arranging transportation to medical appointments, which not only increases care partner burden but also has the potential to jeopardize job security and lead to lost wages.

Another advantage of telemedicine is that it expands access to appropriate care. ${ }^{38,40}$ Persons with neurodegenerative diseases are likely to become homebound as the disease advances, and homebound adults are among the most costly patients in the US healthcare system. ${ }^{41,42}$ The healthcare that homebound adults receive has been described as fragmented, ${ }^{41,42}$ with droughts of healthcare interactions punctuated by the use of costly emergency medical services. Telemedicine provides a means for patients with hallucinations and delusions associated with neurodegenerative disease to receive more continuous healthcare before a crisis requiring emergency management manifests. In patients with $\mathrm{PD}$ and $\mathrm{AD}$, telemedicine is a valuable tool that can facilitate mental healthcare management, including medication changes, referrals for additional therapies and support, administration of cognitive tests, and tele-rehabilitation. ${ }^{40}$ Even among individuals who are not homebound, the number of specialists is limited in certain areas of the US, as they tend to aggregate in urban and coastal areas. ${ }^{43}$ Telemedicine can overcome geographic barriers, granting patients in more remote communities access to specialist care.
Tele-visits involving video can also provide clinicians with insight into the home environment providing benefits comparable to those of a house call or in-depth interview with a care partner. For example, the person can be asked to show what is in their refrigerator, potentially providing a unique perspective of their living conditions. Moreover, conferencing features in telemedicine platforms permit the inclusion of multiple individuals, such as family members and friends, during scheduled appointments. This may allow for the disclosure of symptoms of which the patient is unaware or attempting to hide. Telemedicine, either as a primary means of healthcare or as a complement to inperson office visits, could be potentially beneficial to older patients, especially those with PDP or DRP, by reducing the need for transportation, expanding access to specialists, and allowing providers a unique insight into patients' living environment.

\section{General Considerations Regarding the Use of Telemedicine Among Patients with PDP or DRP}

It must be stated that telemedicine is not suitable for all patients. For example, approximately 10 million elderly individuals living in the US lack technological experience, as defined by not owning or knowing how to use an internet-enabled device, and thus are not ready to engage in videoconferencing. ${ }^{44}$ Approximately 7 million elderly individuals have a physical disability (eg, dementia, difficulty hearing/communicating/seeing) that may impede the use of telemedicine services. ${ }^{44}$ In addition, vulnerable individuals in underserved communities may lack internet access and consequently have limited ability to teleconference. Although a care partner may be able to facilitate communication between the clinician and patient, inperson appointments may still be necessary.

Telemedicine provides an opportunity for healthcare professionals to invite other specialists to participate in and contribute to patient care. The involvement of multiple healthcare providers with differing specialties can provide patients with more comprehensive care. Ideally, patients with DRP or PDP will have a care team comprising a primary care provider, a neurologist, a neuropsychologist, a geriatric psychiatrist, a nurse practitioner, and a social worker. Since many primary care providers prefer to manage the patient alone $^{45}$ and the availability of appropriate specialists might be limited in their geographical region, many patients with neurological disorders are not referred to a specialist. For 
example, the involvement of neuropsychologists and psychiatrists in the care of patients with DRP or PDP is often delayed because patients are typically seen by both a primary care provider and a neurologist prior to being referred to a mental health specialist. With expanded access to appropriate specialists, telemedicine has the potential to shorten the delay during which patients are diagnosed and treated for symptoms of psychosis related to neurodegenerative disease. Furthermore, the use of electronic medical records from multiple specialists in conjunction with telemedicine can help efficiently integrate multidisciplinary care efforts to optimize the treatment plan by providing clinicians with comprehensive monitoring and assessment of patient disease management. ${ }^{46}$ Telemedicine also has the ability to serve more patients than strictly in-person care because unexpected openings in schedule are more easily filled with a tele-visit.

If the patient does have an extended care team, the clinician hosting the telemedicine appointment will need to determine whether any of these individuals should be invited to participate in or consulted in advance of the tele-visit. When working with a multidisciplinary team, it is important to clearly delineate the role of each member in the patient's care. For example, the neurologist could be primarily responsible for addressing emergent motor and cognitive symptoms, the primary care provider with chronic disease management and coordination of care, and the psychiatrist and/or psychiatric nurse practitioner with psychosis, as well as mood or anxiety symptoms.

Telemedicine platforms also provide the opportunity for the inclusion of multiple participants, including those from diverse geographic locations. Possin and colleagues developed a successful telehealth program, The Care Ecosystem, which engaged a team of dementia specialists, including a nurse, a social worker, and a pharmacist. ${ }^{47}$ Participants experienced improved quality of life, fewer emergency department visits, and reduced care partner burden as a result of this team-based telehealth effort. Inviting social workers, for example, could help to engage family/care partners of patients with PDP and DRP in behavioral management strategies. Out-of-town family members who have a regular relationship or regular interactions with the patient, especially during the early development of psychosis, can provide insight into disease progression. Of note, the number of participants should be carefully considered to avoid confusion or distractions caused by multiple people appearing on screen.

\section{Best Practices for Avoiding Technical Issues During Tele-Visits}

In the outpatient setting, technical responsibilities for televisits rest with the end user (eg, patient, care partner, family member). However, front-office staff of the provider are well positioned to provide support to the end user by helping them prepare for the tele-visit along with instructions to resolve common technical issues. A routine "check-in" prior to the tele-visit by the front-office staff may minimize problems and may include calling the patient/care partner the day of the televisit to prepare the patient, verifying phone numbers and/or emails, collecting payments, and explaining the tele-visit process. Once this "check-in" is completed, the provider is notified and the tele-visit can commence as scheduled. Despite proper preparation, problems may still be present during a televisit and contingency plans should be in place. Minimal technology requirements and common troubleshooting scenarios during a tele-visit are presented in Table 1.

Table I Minimal Technology Requirements and Common Troubleshooting Scenarios

\begin{tabular}{|l|l|l|}
\hline $\begin{array}{l}\text { Technical } \\
\text { Requirement }\end{array}$ & Potential Issues & $\begin{array}{l}\text { Potential } \\
\text { Solutions }\end{array}$ \\
\hline $\begin{array}{l}\text { Selection of video } \\
\text { conferencing } \\
\text { applications that are } \\
\text { verified, confidential, } \\
\text { and secure }\end{array}$ & $\begin{array}{l}\text { Lack of technical } \\
\text { readiness may make } \\
\text { a tele-visit open to } \\
\text { unauthorized access }\end{array}$ & $\begin{array}{l}\text { Establish procedures } \\
\text { that ensure Health } \\
\text { Insurance Portability } \\
\text { and Accountability } \\
\text { Act (HIPAA) }\end{array}$ \\
\hline $\begin{array}{l}\text { Familiarize patients } \\
\text { and care partner } \\
\text { with the telehealth } \\
\text { platform to facilitate } \\
\text { a continuous tele- } \\
\text { visit }\end{array}$ & $\begin{array}{l}\text { Problems with } \\
\text { signing into the } \\
\text { telehealth platform, } \\
\text { camera location, and } \\
\text { video disruptions }\end{array}$ & $\begin{array}{l}\text { Provide patients and } \\
\text { care partner detailed } \\
\text { instructions on } \\
\text { accessing, navigating, } \\
\text { and troubleshooting } \\
\text { the telehealth } \\
\text { platform }\end{array}$ \\
\hline $\begin{array}{l}\text { Identify device (eg, } \\
\text { computer, } \\
\text { smartphone, tablet) } \\
\text { with video camera } \\
\text { and connection to } \\
\text { internet }\end{array}$ & $\begin{array}{l}\text { Not all patients or } \\
\text { pare partners } \\
\text { to use these } \\
\text { technologies }\end{array}$ & $\begin{array}{l}\text { Family, friends, or } \\
\text { neighbors may lend } \\
\text { devices or invite the } \\
\text { patient to their } \\
\text { home to use their } \\
\text { devices or internet } \\
\text { connection }\end{array}$ \\
\hline $\begin{array}{l}\text { Backup plan in the } \\
\text { event of technology } \\
\text { breakdown }\end{array}$ & $\begin{array}{l}\text { Loss of internet } \\
\text { access; } \\
\text { malfunctioning } \\
\text { devices }\end{array}$ & $\begin{array}{l}\text { Establish alternative } \\
\text { methods of } \\
\text { communication in } \\
\text { advance (eg, } \\
\text { telephone access) }\end{array}$ \\
\hline
\end{tabular}


Office staff of the provider should ask end users at the time of appointment scheduling which device (eg, phone, computer, tablet) will be used during the tele-visit. If the option exists, devices with larger screens should be recommended (eg, a tablet is preferred to a mobile phone) Along with lack of knowledge of proper use of technological devices in geriatric populations, a socioeconomic digital disparity exists due to the burden associated with affordability of internet access and/or devices hindering telemedicine in elderly patients with low socioeconomic status. Issues stemming from patients not owning or knowing how to use an internet-enabled device can be mitigated by lending the patient a preconfigured device for the televisit and/or accessing the internet via community-based services, such as libraries, churches, or synagogues, or by enlisting the support of technologically savvy family members, friends, or home care staff. However, community internet is often open for anyone to access, and the best approach to avoid these security issues might be to identify family and friends who can support the teleconference platform and provide secure internet access.

Preparation of the tele-visit by provider, patient, and care partner may help to avoid or minimize technological and environmental disruptions during the tele-visit. In advance of the appointment, end users should be provided with (1) clear, written instructions - ideally with accompanying screenshots - on how to access the telehealth platform and (2) a checklist of helpful hints to facilitate connectivity and ease of use. The checklist could include friendly reminders, such as "don't sit in front of a light source," "turn on your camera and microphone," and "ensure that you and your care partner remain in-frame." A document outlining how the tele-visit will unfold may also aid in keeping the patient calm and increase the usefulness of the appointment from a clinical perspective and the willingness of the patient, care partner, or both to engage in remote communication moving forward. If possible in the platform being used, end users should also be instructed to $\log$ on $\geq 15$ minutes prior to the scheduled visit and to contact front-office staff in the event of technical difficulties to avoid unnecessary delays.

Alternative procedures to communicate should be established in the eventuality of technological issues. If image quality is poor or intermittent, a decision could be made to switch to audio only. To prepare for switching to audio only, the clinician should be provided with alternative contact information (eg, landline number) for the patient in advance of the tele-visit. If audio is muted or not working, the clinician could display flashcards with written instructions advising next steps. Proper preparation prior to the tele-visits should help to minimize delays and disruption caused by technological issues.

\section{Evaluating and Diagnosing Patients with PDP or DRP During Tele-Visits}

We suggest an initial in-person visit before starting telemedicine visits whenever possible because a trusting relationship with the clinician may improve adherence to treatment recommendations. Further, a key disadvantage of telemedicine is the inability to perform a complete neurological examination, which is critical for patients with neurodegenerative disease. A neurological exam would ideally include sensory testing and an examination of balance, strength, reflexes, and muscle tone (eg, for rigidity). An initial in-person visit would allow this and is also aligned with the Consolidated Appropriations Act, 2021, which requires patients on Medicare to receive $\geq 1$ in-person mental health visit in the 6 months prior to their first telehealth service to qualify for reimbursement. ${ }^{49}$

To maximize the care team's understanding of the patient's symptoms, the telehealth appointment may be scheduled during the time of day when the patient's symptoms are typically most severe. If possible, clinicians can use the advantage of seeing patients in their home environment by asking patients to show where they were when hallucinations occurred, allowing the clinician to identify any potential triggers for hallucinations or delusions. For example, if a patient's visual hallucination involves seeing bats on the ceiling of their bedroom, it may be related to the proximity of a ceiling fan or smoke detector, which would be helpful for the clinician to observe in order to suggest an intervention.

The patient's care partner and family are critical sources of information before, during, and after the televisit. If patient consent can be obtained ahead of time, a phone call between the clinician and care partner in advance of the appointment could be used for information gathering and could help to avoid potential antagonism between the patient and care partner during the tele-visit. With the proper instruction, the care partner could also be tasked with completing behavioral and cognitive assessments and vital sign measurements (eg, blood pressure, heart rate). During the tele-visit, the care partner should also be on screen, because he or she may assist in facilitating communication between the patient and clinician. 
Box I Provider Preparation for Emergency Situations

- Keep the contact information for emergency services in the patient's region and phone number for the local government office on file

- Familiarize self and staff with the patient's local civil commitment regulations

- Develop and train staff on procedures for the management of mental

health emergencies

- Make pre-emptive arrangements with care partners and family members to assist with civil commitments or other emergencies

The care partner may also provide insight into the patient's responses and reactions to the clinician's questions, and the care partner-patient interaction during the tele-visit may provide insight into the patient's status. For instance, if the patient were to say that "Everything is fine," the care partner could interject, advising of any changes (eg, frequency/severity of symptoms). The care partner's body language could also speak volumes, prompting the clinician to probe more deeply. After the tele-visit, if needed, the care partner, could be solicited to corroborate information acquired during the evaluation and diagnosis of a patient with PDP or DRP.

Consistent with both American Psychiatric Association (APA) and International Parkinson Disease and Movement Disorder Society guidelines, ${ }^{32,33}$ we recommend that providers have pre-established protocols in place for emergencies ahead of any telehealth visit. Provider, patient, and family member/care partner telephone numbers, patient location, and available emergency resources should be available to all parties prior to and during the visit (Box 1). ${ }^{48}$

\section{Treating and Monitoring Patients with PDP or DRP During Tele-Visits}

Treatment options provided via telemedicine should be nothing less than what would be offered to the patient in person. Clinicians should take extra care to ensure that the patient or care partner understands the treatment recommendations being discussed. Although providing the patient or care partner with printed information is standard during in-person visits, doing so is a challenge in the telemedicine environment. Strategies to help ensure that recommendations are understood and followed include asking the care partner to take notes during the tele-visit, emailing written summaries and handouts to the patient and care partner post-visit, and providing contact information for the patient and care partner to use in the event of follow-up questions. Family members and other care partners should be encouraged to systematically monitor vital signs and any medication side effects that emerge. This can be facilitated by the purchase of vital sign measuring equipment, when appropriate, or a journal to track side effects.

Increased awareness on the part of the primary care provider and the family/care partners of patients regarding how psychosis presents, screening tools available to detect psychosis, and telespecialist availability can speed referrals and diagnosis of PDP or DRP. For example, assessment tools suggested by the primary care provider can be completed ahead of the telehealth visit and used as a screening tool. During the tele-visit, the clinician should monitor the patient for behavior that might indicate possible symptoms of psychosis. Subtle cues may include darting eyes, paranoia or distrust surrounding the evaluation or close friends/family, disorganized speech, and withdrawal.

Healthcare providers should also provide additional care and support to those patients taking medication by monitoring for effectiveness and side effects during televisits. Patients receiving treatment with antipsychotics, particularly off-label antipsychotics, should also be monitored for negative side effects including tardive dyskinesia. $^{50-52}$ The APA has specific monitoring guidelines, including use of standardized rating scales for tardive dyskinesia. ${ }^{53}$ If applicable, side effects associated with antipsychotics should be monitored and discussed regularly with the patient and care partner.

In-person visits also typically conclude with an immediate plan for a follow-up visit. To maintain continuous care, we recommend that front-office staff phone the patient/care partner soon after the tele-visit to schedule a follow-up appointment. Neuropsychological evaluation can be repeated to help monitor cognitive and neuropsychiatric changes over time. Regular, consistent follow-up visits are possible through telemedicine without the need for the patient to travel and are associated with an increased sense of security and comfort for the patient by allowing him or her to remain at home. ${ }^{54}$ Behavioral health follow-up visits, particularly those to ensure medication adherence or discuss medication adjustments, have been successfully conducted virtually. ${ }^{55}$

Virtual follow-up visits may also be associated with a lower no-show rate, in relation to in-person follow-up visits. ${ }^{56,57}$ During the COVID-19 pandemic, a low rate of no-shows for telehealth visits in comparison with inperson visits was sustained and was lower than those 
prior to the COVID-19 pandemic. ${ }^{57}$ Encouragingly, perception of and satisfaction with treatment via telemedicine among elderly adults and among those with neurodegenerative disease are favorable. ${ }^{54,58,59}$ One report found that more than half of patients with Parkinson's disease who had never received telehealth care expressed interest in telemedicine, ${ }^{60}$ and $85-100 \%$ of those receiving telemedicine expressed satisfaction with the care received. ${ }^{60,61}$

\section{Conclusions and Future Directions}

Telemedicine can serve as a valuable complement to traditional in-person care practices for the diagnosis and management of hallucinations and delusions associated with neurodegenerative disease. Although telemedicine may not be suitable for all patients, it offers several advantages over in-person visits, including the opportunity to extend care to homebound individuals and to involve teams of specialists from multiple geographic locations.

Technical issues associated with telemedicine may be partially offset by providing the patient or care partner with clear directions and a checklist of helpful hints ahead of any tele-visit to ensure connectivity and access to the videoconferencing platform. Similar to in-person care, care partners can be a critical source of information in the evaluation, diagnosis, and ongoing management of patients with PDP or DRP. Clinicians should take extra care to ensure that the patient or care partner understands the treatment recommendations discussed during the televisit and to encourage regular follow-up tele-visits, tailored to suit individual patient needs to monitor the patient over time.

Rapid changes in policy to expand access to telehealth occurred during the COVID-19 pandemic. ${ }^{15}$ Long-term policy changes, including incorporation of telemedicine reimbursement for patients residing in both rural and urban settings, will be required to allow continued access for patients who can benefit from telemedicine use. Although telemedicine can be used effectively and offers several advantages over in-person care for patients with PDP or DRP, there are several remaining challenges that need to be addressed to be able to extend this opportunity to more patients in need of treatment. Technological limitations still exist because of a lack of universal access to the internet/advanced technological devices, particularly for elderly patients. Education is needed for patients and family/care partners who are uncomfortable using or unfamiliar with technology. Although care partners are adept at recognizing sudden changes in a loved one's behavior or cognitive abilities, they may not know the best path for seeking consultation. Thus, education tailored to the lay community is also needed.

Although the long-term outlook of telemedicine for older patients with degenerative disease in the outpatient setting remains unknown, these recommendations highlight ways to maximize use of virtual healthcare and encourage care providers to use telemedicine to maintain consistent and high-quality care remotely.

\section{Abbreviations}

APA, American Psychiatric Association; DRP, dementiarelated psychosis; PDP, Parkinson's disease psychosis.

\section{Data Sharing Statement}

No data were collected during the development of this manuscript.

\section{Acknowledgments}

Medical writing and editorial support, under the direction of the authors, were provided by Tiffany DeSimone, $\mathrm{PhD}$, and Dena McWain of Ashfield MedComms, an Ashfield Health company.

\section{Author Contributions}

All authors made a significant contribution to the work reported, whether that is in the conception, analysis and interpretation, or in all these areas; took part in drafting, revising or critically reviewing the article; gave final approval of the version to be published; have agreed on the journal to which the article has been submitted; and agree to be accountable for all aspects of the work.

\section{Funding}

Acadia Pharmaceuticals Inc. funded medical writing and editorial support for this manuscript, as well as the advisory board meeting during which the authors initially discussed ideas for this paper.

\section{Disclosure}

CC: Advisory boards for AbbVie, Acadia Pharmaceuticals Inc, Alkermes, Eisai, Intracellular, Ironshore, Janssen, Jazz, Neurocrine, Noven, Otsuka, Takeda, and Teva; consultant for Corium, Janssen, Neurocrine, and Otsuka; grant/research support from Acadia Pharmaceuticals Inc, Axsome, Karuna Therapeutics, Harmony, Genomind, and Neurocrine; speakers bureau for AbbVie, Acadia Pharmaceuticals Inc, Alkermes, Corium, Eisai, 
Intracellular, Ironshore, Janssen, Jazz, Lundbeck, Neurocrine, Noven, Otsuka, Sunovion, Takeda, and Teva. LS: Advisory board for Acadia Pharmaceuticals Inc and educational speaker for Biogen. SB: Advisory board and speakers bureau for Acadia Pharmaceuticals Inc. JGF: Advisory boards and speaker for AbbVie, Acadia Pharmaceuticals Inc, Acorda, Kyowa Kirin, Neurocrine, Supernus, Sunovion, and Teva. ASR: Advisory board and speakers bureau for Acadia Pharmaceuticals Inc. GG: Consultant for Acadia Pharmaceuticals Inc, Alkahest, Avanir, Axsome, Biogen, Bioxcel, Genentech, Karuna, Lundbeck, Otsuka, Roche, and Takeda; research support from NIA, Janssen, and Roche; safety monitoring committee for Anavex, EryDel, Intra-Cellular Therapies, Merck, and Newron; speakers bureau for Acadia Pharmaceuticals Inc and Biogen. WW: Speakers bureau: Pfizer, Merck and Sanofi: Vaccines; Biohaven and AbbVie: Migraines. Consultant: Pfizer, Merck, and Sanofi: Vaccines; GSK: $\mathrm{OA} /$ Pain and Vaccines. The authors report no other conflicts of interest in this work.

\section{References}

1. Plassman BL, Langa KM, Fisher GG, et al. Prevalence of dementia in the United States: the aging, demographics, and memory study. Neuroepidemiology. 2007;29(1-2):125-132. doi:10.1159/000109998

2. Goodman RA, Lochner KA, Thambisetty M, Wingo TS, Posner SF, Ling SM. Prevalence of dementia subtypes in United States Medicare fee-for-service beneficiaries, 2011-2013. Alzheimers Dement. 2017;13(1):28-37. doi:10.1016/j.jalz.2016.04.002

3. Hebert LE, Weuve J, Scherr PA, Evans DA. Alzheimer disease in the United States (2010-2050) estimated using the 2010 census. Neurology. 2013;80(19):1778-1783. doi:10.1212/ WNL.0b013e31828726f5

4. Yang W, Hamilton JL, Kopil C, et al. Current and projected future economic burden of Parkinson's disease in the U.S. NPJ Parkinsons Dis. 2020;6(1):15. doi:10.1038/s41531-020-0117-1

5. Forsaa EB, Larsen JP, Wentzel-Larsen T, et al. A 12-year population-based study of psychosis in Parkinson disease. Arch Neurol. 2010;67(8):996-1001. doi:10.1001/archneurol.2010.166

6. Connors MH, Ames D, Woodward M, Brodaty H. Psychosis and clinical outcomes in Alzheimer disease: a longitudinal study. Am J Geriatr Psychiatry. 2018;26(3):304-313. doi:10.1016/j.jagp.2017.10.011

7. Scarmeas N, Brandt J, Albert M, et al. Delusions and hallucinations are associated with worse outcome in Alzheimer disease. Arch Neurol. 2005;62(10):1601-1608. doi:10.1001/archneur.62.10.1601

8. Russ TC, Batty GD, Starr JM. Cognitive and behavioural predictors of survival in Alzheimer disease: results from a sample of treated patients in a tertiary-referral memory clinic. Int J Geriatr Psychiatry. 2012;27(8):844-853. doi:10.1002/gps.2795

9. Peters ME, Schwartz S, Han D, et al. Neuropsychiatric symptoms as predictors of progression to severe Alzheimer's dementia and death: the Cache County Dementia progression study. Am J Psychiatry. 2015;172(5):460-465. doi:10.1176/appi.ajp.2014.14040480

10. Choi A, Ballard C, Martyr A, et al. The impact of auditory hallucinations on "living well" with dementia: findings from the IDEAL programme. Int $J$ Geriatr Psychiatry. 2021;36(9):1370-1377. doi:10.1002/gps.5533
11. Goetz CG, Fan W, Leurgans S. Antipsychotic medication treatment for mild hallucinations in Parkinson's disease: positive impact on long-term worsening. Mov Disord. 2008;23(11):1541-1545. doi: $10.1002 / \mathrm{mds} .22132$

12. Czeisler ME, Marynak K, Clarke KEN, et al. Delay or avoidance of medical care because of COVID-19-related concerns - United States, June 2020. MMWR Morb Mortal Wkly Rep. 2020;69(36):1250-1257. doi:10.15585/mmwr.mm6936a4

13. World Health Organization. The impact of the COVID-19 pandemic on noncommunicable disease resources and services: results of a rapid assessment; 2020. Available from: https://www.who.int/pub lications/i/item/ncds-covid-rapid-assessment. Accessed April 21, 2021.

14. Mehrotra A, Chernew ME, Linetsky D, Hatch H, Cutler D, Schneider EC. The impact of COVID-19 on outpatient visits in 2020: visits remained stable, despite a late surge in cases; 2021. Available from: https://www.commonwealthfund.org/publications/ 2021/feb/impact-covid-19-outpatient-visits-2020-visits-stable-despite -late-surge. Accessed December 6, 2021.

15. Centers for Medicare \& Medicaid Services. Medicare telemedicine health care provider fact sheet; 2020. Available from: https://www. $\mathrm{cms}$.gov/newsroom/fact-sheets/medicare-telemedicine-health-careprovider-fact-sheet. Accessed April 21, 2021.

16. Fasano A, Antonini A, Katzenschlager R, et al. Management of advanced therapies in Parkinson's disease patients in times of humanitarian crisis: the COVID-19 experience. Mov Disord Clin Pract. 2020;7(4):361-372. doi:10.1002/mdc3.12965

17. Koonin LM, Hoots B, Tsang CA, et al. Trends in the use of telehealth during the emergence of the COVID-19 pandemic - United States, January-March 2020. MMWR Morb Mortal Wkly Rep. 2020;69 (43):1595-1599. doi:10.15585/mmwr.mm6943a3

18. Patel SY, Mehrotra A, Huskamp HA, Uscher-Pines L, Ganguli I, Barnett ML. Trends in outpatient care delivery and telemedicine during the COVID-19 pandemic in the US. JAMA Intern Med. 2021;181(3):388-391. doi:10.1001/jamainternmed.2020.5928

19. Shore JY, Yellowlees P. The COVID-19 pandemic and virtual care: the transformation of psychiatry. Psychiatr News. 2021;56(5):19-34. doi:10.1176/appi.pn.2021.5.30

20. Moran M. After the pandemic: What Will the 'New Normal' be in psychiatry? Psychiatr News. 2021;56(5):1.

21. Barton C, Morris R, Rothlind J, Yaffe K. Video-telemedicine in a memory disorders clinic: evaluation and management of rural elders with cognitive impairment. Telemed J E-Health. 2011;17 (10):789-793. doi:10.1089/tmj.2011.0083

22. Azad N, Amos S, Milne K, Power B. Telemedicine in a rural memory disorder clinic-remote management of patients with dementia. Can Geriatr J. 2012;15(4):96-100. doi:10.5770/cgj.15.28

23. Martin-Khan M, Flicker L, Wootton R, et al. The diagnostic accuracy of telegeriatrics for the diagnosis of dementia via video conferencing. J Am Med Dir Assoc. 2012;13(5):487 e419-424. doi:10.1016/j. jamda.2012.03.004

24. Hunter MB, Jenkins N, Dolan C, Pullen H, Ritchie C, Muniz-Terrera G. Reliability of telephone and videoconference methods of cognitive assessment in older adults with and without dementia. $J$ Alzheimers Dis. 2021;81(4):1625-1647. doi:10.3233/JAD-210088

25. Carotenuto A, Traini E, Fasanaro AM, Battineni G, Amenta F. Teleneuropsychological assessment of Alzheimer's disease. J Pers Med. 2021;11(8):688. doi:10.3390/jpm11080688

26. Myers TL, Tarolli CG, Adams JL, et al. Video-based Parkinson's disease assessments in a nationwide cohort of Fox insight participants. Clin Park Relat Disord. 2021;4:100094. doi:10.1016/j. prdoa.2021.100094

27. Beck CA, Beran DB, Biglan KM, et al. National randomized controlled trial of virtual house calls for Parkinson disease. Neurology. 2017;89(11):1152-1161. doi:10.1212/WNL.0000000000004357 
28. Yi JS, Pittman C, Price CL, Nieman CL, Oh ES. Telemedicine and dementia care: a systematic review of barriers and facilitators. $J \mathrm{Am}$ Med Dir Assoc. 2021;22(7):1396-1402.e18. doi:10.1016/j. jamda.2021.03.015

29. Sharp IR, Kobak KA, Osman DA. The use of videoconferencing with patients with psychosis: a review of the literature. Ann Gen Psychiatry. 2011;10(1):14. doi:10.1186/1744-859X-10-14

30. Shen J, Kobak KA, Zhao Y, Alexander MM, Kane JM. Use of remote centralized raters via live 2-way video in a multicenter clinical trial for schizophrenia. J Clin Psychopharmacol. 2008;28(6):691-693. doi:10.1097/JCP.0b013e31818c9ba3

31. Pandina GJ, Lindenmayer JP, Lull J, et al. A randomized, placebo-controlled study to assess the efficacy and safety of 3 doses of paliperidone palmitate in adults with acutely exacerbated schizophrenia. J Clin Psychopharmacol. 2010;30(3):235-244. doi:10.1097/JCP.0b013e3181dd3103

32. International Parkinson and Movement Disorder Society. International Parkinson and movement disorder society steps for conducting a telemedicine visit; 2020. Available from: https://www. movementdisorders.org/MDS/About/Committees-Other-Groups /Telemedicine-in-Your-Movement-Disorders-Practice-A-Step-byStep-Guide/Step-5.htm. Accessed April 29, 2021.

33. American Psychiatric Association. Telepsychiatry toolkit; 2021. Available from: https://www.psychiatry.org/psychiatrists/practice/tele psychiatry/toolkit. Accessed June 8, 2021.

34. American Medical Association. Telehealth implementation playbook; 2020. Available from: https://www.ama-assn.org/system/files/202004/ama-telehealth-playbook.pdf. Accessed April 21, 2021.

35. American Academy of Family Physicians. A toolkit for building and growing a sustainable telehealth program in your practice; 2020. Available from: https://www.aafp.org/dam/AAFP/documents/prac tice_management/telehealth/2020-AAFP-Telehealth-Toolkit.pdf. Accessed April 21, 2021.

36. Batsis JA, DiMilia PR, Seo LM, et al. Effectiveness of ambulatory telemedicine care in older adults: a systematic review. $J$ Am Geriatr Soc. 2019;67(8):1737-1749. doi:10.1111/jgs.15959

37. Wilkinson JR, Spindler M, Wood SM, et al. High patient satisfaction with telehealth in Parkinson disease: a randomized controlled study. Neurol Clin Pract. 2016;6(3):241-251. doi:10.1212/CPJ.0000000 000000252

38. Adams JL, Myers TL, Waddell EM, Spear KL, Schneider RB. Telemedicine: a valuable tool in neurodegenerative diseases. Curr Geriatr Rep. 2020;9(2):72-81. doi:10.1007/s13670-020-00311-z

39. Uc EY, Rizzo M, O'Shea AMJ, Anderson SW, Dawson JD. Longitudinal decline of driving safety in Parkinson disease. Neurology. 2017;89(19):1951-1958. doi:10.1212/WNL.0000000 000004629

40. Deeb W, Hess CW, Gamez N, Patel B, Moore K, Armstrong MJ. Response to telemedicine visits from patients with Parkinsonism during the COVID-19 pandemic on postvisit surveys. J Patient Exp. 2021;8:2374373521997224. doi:10.1177/2374373521997224

41. Leff B, Carlson CM, Saliba D, Ritchie C. The invisible homebound: setting quality-of-care standards for home-based primary and palliative care. Health Aff. 2015;34(1):21-29. doi:10.1377/ hlthaff.2014.1008

42. Musich S, Wang SS, Hawkins K, Yeh CS. Homebound older adults: prevalence, characteristics, health care utilization and quality of care. Geriatr Nurs. 2015;36(6):445-450. doi:10.1016/j.gerinurse.20 15.06.013

43. Dorsey ER, George BP, Leff B, Willis AW. The coming crisis: obtaining care for the growing burden of neurodegenerative conditions. Neurology. 2013;80(21):1989-1996. doi:10.1212/ WNL.0b013e318293e2ce
44. Lam K, Lu AD, Shi Y, Covinsky KE. Assessing telemedicine unreadiness among older adults in the United States during the COVID-19 pandemic. JAMA Intern Med. 2020;180(10):1389-1391. doi:10.1001/ jamainternmed.2020.2671

45. Swarztrauber K, Vickrey BG. Do neurologists and primary care physicians agree on the extent of specialty involvement of patients referred to neurologists? J Gen Intern Med. 2004;19(6):654-661. doi:10.1111/j.1525-1497.2004.30535.x

46. Lin S, Sattler A, Smith M. Retooling primary care in the COVID-19 era. Mayo Clin Proc. 2020;95(9):1831-1834. doi:10.1016/j. mayocp.2020.06.050

47. Possin KL, Merrilees JJ, Dulaney S, et al. Effect of collaborative dementia care via telephone and internet on quality of life, caregiver well-being, and health care use: the care ecosystem randomized clinical trial. JAMA Intern Med. 2019;179(12):1658. doi:10.1001/ jamainternmed.2019.4101

48. Shore JH, Yellowlees $\mathrm{P}$, Caudill $\mathrm{R}$, et al. Best practices in videoconferencing-based telemental health April 2018. Telemed $J$ E-Health. 2018;24(11):827-832. doi:10.1089/tmj.2018.0237

49. American Hospital Association. Detailed summary of health provisions in consolidated appropriations act, 2021; 2021. Available from: https://www.aha.org/system/files/media/file/2020/12/detailedsummary-health-provisions-consolidated-appropriations-act-2021bulletin-12-22-20.pdf. Accessed April 21, 2021.

50. Schneider LS, Dagerman K, Insel PS. Efficacy and adverse effects of atypical antipsychotics for dementia: meta-analysis of randomized, placebo-controlled trials. Am $J$ Geriatr Psychiatry. 2006;14 (3):191-210. doi:10.1097/01.JGP.0000200589.01396.6d

51. Jeste DV. Tardive dyskinesia in older patients. $J$ Clin Psychiatry. 2000;61(Suppl 4):27-32.

52. Cornett EM, Novitch M, Kaye AD, Kata V, Kaye AM. MedicationInduced Tardive Dyskinesia: a review and update. Ochsner J. 2017;17(2):162-174.

53. Keepers GA, Fochtmann LJ, Anzia JM, et al. The American Psychiatric Association practice guideline for the treatment of patients with schizophrenia. Am J Psychiatry. 2020;177(9):868-872. doi:10.1176/appi.ajp.2020.177901

54. Eisenberg JL, Hou JG, Barbour PJ. Current perspectives on the role of telemedicine in the management of Parkinson's disease. Smart Homecare Technol Telehealth. 2018;5:1-12. doi:10.2147/SHTT.S152018

55. Gire N, Farooq S, Naeem F, et al. mHealth based interventions for the assessment and treatment of psychotic disorders: a systematic review. Mhealth. 2017;3:33. doi:10.21037/mhealth.2017.07.03

56. Dorsey ER, Venkataraman V, Grana MJ, et al. Randomized controlled clinical trial of "virtual house calls" for Parkinson disease. JAMA Neurol. 2013;70(5):565-570. doi:10.1001/jamaneurol.2013.123

57. Drerup B, Espenschied J, Wiedemer J, Hamilton L. Reduced no-show rates and sustained patient satisfaction of telehealth during the COVID-19 pandemic. Telemed $J$ E-Health. 2021;25(1):40-44. doi: $10.1089 / \mathrm{tmj} .2021 .0002$

58. Mammen JR, Elson MJ, Java JJ, et al. Patient and physician perceptions of virtual visits for Parkinson's disease: a qualitative study. Telemed J E-Health. 2018;24(4):255-267. doi:10.1089/tmj.2017.0119

59. Spear KL, Auinger P, Simone R, Dorsey ER, Francis J. Patient views on telemedicine for Parkinson disease. J Parkinsons Dis. 2019;9 (2):401-404. doi:10.3233/JPD-181557

60. Qiang JK, Marras C. Telemedicine in Parkinson's disease: a patient perspective at a tertiary care centre. Parkinsonism Relat Disord. 2015;21(5):525-528. doi:10.1016/j.parkreldis.2015.02.018

61. Venkataraman V, Donohue SJ, Biglan KM, Wicks P, Dorsey ER. Virtual visits for Parkinson disease: a case series. Neurol Clin Pract. 2014;4 (2):146-152. doi:10.1212/01.CPJ.0000437937.63347.5a 


\section{Publish your work in this journal}

The International Journal of General Medicine is an international, peer-reviewed open-access journal that focuses on general and internal medicine, pathogenesis, epidemiology, diagnosis, monitoring and treatment protocols. The journal is characterized by the rapid reporting of reviews, original research and clinical studies across all disease areas. The manuscript management system is completely online and includes a very quick and fair peer-review system, which is all easy to use. Visit http://www.dovepress.com/ testimonials.php to read real quotes from published authors. 